\title{
SAFETY PRACTICES OF CONSTRUCTION COMPANIES IN RIVERS STATE, NIGERIA
}

Volume 4 | Issue 1 | 2021

\author{
Ilodeami M. Mophoi, \\ E. I. Achalu, \\ G. O. Ekenedo \\ Department of Human Kinetics and Health Education, \\ Faculty of Education, \\ University of Port Harcourt, \\ Nigeria
}

\begin{abstract}
:
This study investigated safety practices of construction companies in Rivers state. A descriptive cross-sectional design was used. The population of the study consisted 2276 workers from 10 construction companies in Rivers state. A sample of 455 construction workers was drawn using clustered sampling technique. Two research questions were answered and two null hypotheses were tested at 0.05 level of significance. The instrument for data collection was a structured and validated questionnaire. An instrument reliability index of 0.78 was obtained through PPMC technique. The data generated from the instrument were analyzed using descriptive statistics to answer the research questions and inferential statistics to test the null hypothesis. The results of the study showed that safety practices among construction companies in Rivers state is above average based on location and size of construction companies. Based on the findings, it was concluded that there is still enough room for improvement in safety practices of the construction industry in Rivers state. It was therefore recommended that efforts should be intensified by contracting construction firms in devising improved strategy to determine and forestall hazard inherent in a given project before embarking on it.
\end{abstract}

Keywords: safety, practices, construction, companies, industry

\section{Background to the Study}

The construction industry is considered as one of the most hazardous industrial sectors in many parts of the world where workers are more prone to workplace accidents. The International Labour Organization (ILO) estimated that at least 60,000 fatal accidents occur annually on construction sites around the world which implies that, in all workfatal related accidents across the globe, one in six can be found on construction sites.

i Correspondence: email akasm29@gmail.com 
Similarly, the global trade union federation puts the figure much higher at 108,000 with construction sites responsible for $30 \%$ of all work-related accidents. Hence, the renewed call on proper management of safety practices in construction companies across the globe (Mopho, 2020).

Most notably, work-related accidents do not only arise from unsafe work conditions but also from unsafe human behaviour at work such as: carelessness, tiredness, stress, lack of concentration, fear, including work cuts (cutting corners). Obviously, health cannot be promoted outside safety practices, thus the need to understand the management of safety practices as a joint effort between employers and employees in ensuring a complete state of physical, emotional and mental well-being (social health in the workplace) of employees at work. It is on the premise of the above fact that safety was defined as the state of being certain that adverse effects will not be caused by some agents under defined conditions (Anupama \& Pratibha in Mopho, 2020).

More so, workplace safety practices can be described as any method or techniques or process that minimize unwanted events (accidents) in an industrial concern. It can also be referred to as a process of industrial safety. So, in the context of this study, industrial safety is the science and art of identifying, evaluating and controlling construction site hazards. It is imperative to note that defining the essence of safety is enormous and cannot be overemphasized or underestimated in the workplace such as the construction companies. More so, as the construction industry is currently being recognized as a major economic force in most developing countries such as Kenya, Malaysia and Nigeria (Mopho, 2020; Rahim, Hamid, Yusuf \& Singh, 2014).

Recently, in an unfortunate development in the construction industry in Nigeria, a seven story building under construction in Woji Road GRA Phase II, Port Harcourt, Rivers state collapsed and killed over 15 workers. In an aftermath action, the Nigerian Institute of Builders (NIOB) had a National conference on health and safety in the building construction industry in a view to proffering needed solutions at this time of fatal accidents taking place on construction sites and in construction companies due to non-implementation of core safety practices. From this one too many fatal accidents and injuries occurring across Nigeria and other developing countries in construction companies, it is obvious that the actual economic capacity of the construction industry will create dire economic implications due to loss of productivity (Mopho, 2020).

Notably, from the above development there is little to be observed on safety practices at construction sites in developing countries. Swuste, Gulijk, Zwaard and Ostendorp, (2014) are incorporating a fuller accounting of tasks, the Entropy Model of accident causation demonstrates that safety and productivity are bound together. The above researchers viewed risk as being linked to negative outcomes such as regret, loss and damage. Following the above development, Mopho (2020) stated here that each time a process is carried out, deviations may occur that have the potential to introduce additional hazards. In this case workers are not spared as they also experience degradation in the form of fatigue, variable vigilance/concentration or loss of physical capacity. 
As system factors degrade, the probability of an accident rises exponentially, as opined by Swuste, et al., (2014). Swuste, et al., (2014) posited therefore that concurrently, the firm's ability to be productive at the same rate as the rising of accidents is to a large extent not feasible because the quality of system factors also affect productivity. In the arguments of Swuste, et al., (2014) an example was given with the probability that if people (workers) are ill or fatigue, they cannot work efficiently. Mopho (2020) equally apply Swuste, et al., (2014) premise to work equipment, and to state the obvious that if workplace equipment is not maintained it cannot generate optimum levels of output; degradation therefore will have negative impact on organizational safety and performance. It is therefore paramount from the foregoing to find out; if there has been any improvement in safety practices in construction companies in a country like Nigeria, to this end, this study is key.

\section{Statement of the Problem}

It is alarming and demeaning to discover from research evidence that an average of 6.5 million people work at approximately 252,000 construction sites across the globe on any given day and the fatal injury rate for the construction industry is higher than any national average for all industries put together. This inadequacy in the construction industry has been attributed to factors such as: inadequate personal protective equipment (PPE), poor maintenance of personal protective gear, lack of top management support, no employees' assistance programs (EAP) in the management of safety practices, inadequate welfare facilities, unawareness of safety practices among the workers and lack of equipped first Aid Kits on construction sites. Now, the question is, why will any construction company be found culpable of not properly implementing safety practice due to the aforementioned factors? There has been different anecdotal evidence observed to have answered this question. In some of the observed construction companies, location has been observed as an underpinning variable of poor safety practices while in some others, size of construction companies makes the difference in construction companies that effectively put safety practices to use and those that do not.

Hence, what motivated the researcher was, how can empirical evidence demonstrate the difference in safety practices in construction companies? Put differently, the study was poised to empirically unravel the imbalances anecdotally observed in safety practices in construction companies in the different parts of Nigeria with specific targets on construction companies in Rivers state.

\subsection{Aim and Objectives of the Study}

This study investigated safety practices of construction companies in Rivers state. Specifically, the objectives were to:

1) ascertain the difference in safety practices based on the location of construction companies in Rivers state, Nigeria; and,

2) establish the difference in safety practices based on the size of construction companies in Rivers state, Nigeria. 


\subsection{Research Questions}

1) What is the difference in safety practices based on the location of construction companies in Rivers state, Nigeria?

2) What is the difference in safety practices based on the size of construction companies in Rivers state, Nigeria?

\subsection{Hypotheses}

1) There is no significant difference in the safety practice based on the location of construction companies in Rivers state, Nigeria.

2) There is no significant difference in the safety practice based on the size of construction companies in Rivers state, Nigeria.

\section{Conceptual Framework}

The concepts of this study are hinged on: construction industry, safety policies, programmes and practice, safety and workplace safety; fundamental principles of hazard and risk, as well as construction industry health and safety in the light of safety practices of construction companies in Rivers state as diagrammatically represented below.

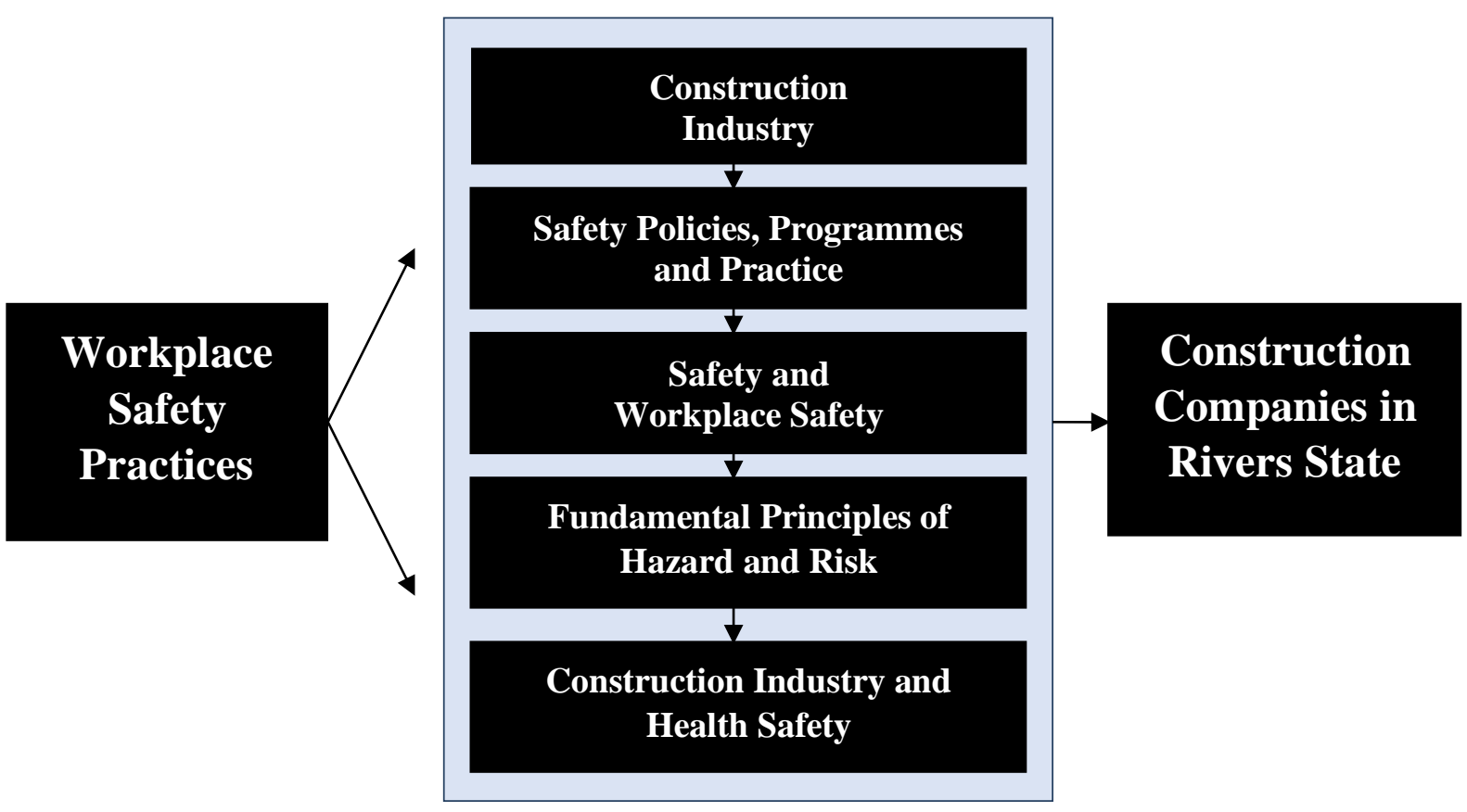

Figure 1: Conceptual Framework

(Source: Researchers' conceptualization, 2020)

\section{The Construction Industry}

Construction industry can be referred to as firms that create buildings for habitation and commercial purpose, inclusive are public works for example roads, bridges, tunnels, dams or airports (ILO, 2015). This is in line with Mopho (2020) who noted that the task of 
the construction industry covers a wide range of activities with different types of structures. These tasks according to Mopho (2020) include but not limited to building, maintenance, renovation and demolition work, as well as construction of a new office block, conversion of old building into flats, installation of new electrical system into an old factory, dismantling of a derelict. It also includes some construction works which are very small in scale for example addition of a small extension structure to a community hall is house building as well as vast construction works such as building bridges, dams, and roads (Mopho, 2020).

In view of the hazardous and risky nature of the construction industry, International Labour Organization (ILO) has International Standards on the regulation of safety in the construction industry. They include Safety and Health in construction convention C167, supported by safety and health in construction recommendation R175 including its associated code of practice. Also, in existence additional to the general principle of occupational safety and health convention C155, National Examination board of Occupational Safety and Health (Mopho, 2020; Nebosh, 2013).

\section{Safety Policies, Programmes and Practice}

Safety policies are the written principles and directives for course of actions to be adopted and also followed by a given company in tandem with best practices of ensuring the protection of lives and properties as well as productivity. This was acknowledged by Jain and Rao, (2015) every company must have a written safety policy. This policy document refers to the principle and directive for course of actions to be adopted and also followed by the said company. Jain, et al., (2015) further noted that policy supersedes rules and practices which emanates from the company's policy document with the following features forming the components of the policy:

1) spelt out long range objectives of the company;

2) every management level personnel without exception must believe in the policy;

3) the policy should be accepted and committed at every level in the company, for the purpose of daily actions;

4) the scope for decisions and descriptions at lower management levels should be indicated in the policy; and,

5) safety policy should form a major part of a company's management policy

Jain and Rao as cited by Mopho (2020) reasoned further that safety policy should include the following: there should be intent and desire of management to achieve safety of personnel and plant. This has to do with management active concern with regards to safety;
a) The scope of safety activities to be covered;
b) Organizational responsibilities and accountability;
c) Safety authority;
d) Safety documentation;
e) Rules, acts including standards; and,
f) Safety audit team (external and internal) safety auditors. 
To buttress the foregoing, Astutis (2017) affirmed that every organization employing people in jobs of a physical nature and/or in potentially hazards conditions is required to have an integrated safety policy. This was substantiated in the thinking of Muiruri and Mulinge, (2014) who observed that site managers in the construction will have a written safety policy for the use of their enterprise/ organization, this will enable them to set out the safety and health standards with objectives to achieve it. The policy will make provision for an authority to be bestowed or conferred with the responsibilities of management and supervision to workers at all levels to see that they are carried out. They went further with the view or opinion that construction safety policy is something that must be developed by every site manager including the operating company before beginning any construction work.

In their point of view, (Mopho, 2020; Astutis, 2017; Muiruri \&Mulinge, 2014) states that, after developing the safety plan, it should be used as training program that every worker on construction site should partake in the training before embarking on any job on construction site irrespective of how simple their role may be. Meetings on construction sites, for example, tool box meetings or pep-talks are essential to the end that safety policies will be placed side by side with ongoing training and retraining for capacity development.

\section{Safety and Workplace Safety}

Safety is connected with people's life and property including the general situation of development and stability. Safety encompasses the prevention of accidents, promotion of occupational health, prevention of environmental pollution including security of workplace and equipment. It deals with freedom from hazards or conditions (situations) that have the potential (enablement), to cause injury, disease, economic loss or damage to properties and environment inclusive.

As substantiated by Anupama and Pratibha, (2010) safety is the state of being safe. Anupama, et al., (2010) further posited that safety is the state of being certain that adverse effect will not be caused by some agents under defined conditions. In the point of view of Anupama, et al., (2010) safety was defined as any method or technique or process which can minimize unwanted events (accident). In an industrial concern, safety may be referred to as a method, technique or process of industrial safety. As acknowledged by Mopho (2020) as well as Anupama, et al., (2010) industrial safety is the science and art of identifying, evaluating and controlling workshop hazards. It includes measures to prevent human exposure to chemical and physical agents as well as faulty or unsafe work practices. 
Table 1: Fundamental Principles of Hazard and Risk

\begin{tabular}{|c|c|}
\hline Hazard & Possible Harmful Effects \\
\hline $\begin{array}{l}\text { Powered tools and } \\
\text { non-powered tools, including } \\
\text { jackhammers, bolt-cutters and } \\
\text { hand-held cutting saws. }\end{array}$ & $\begin{array}{l}\text { Exhaust fumes } \\
\text { Contact with electrical conductors } \\
\text { Contact with cutting blades } \\
\text { Part of equipment breaking up, flying material. }\end{array}$ \\
\hline Working at height. & Falls with potential for serious or fatal injury \\
\hline $\begin{array}{l}\text { Climbing on heavy construction } \\
\text { equipment. }\end{array}$ & Falls with potential for serious or fatal injury. \\
\hline Excavations. & $\begin{array}{l}\text { Collapse of excavations can bury people, causing crushing or } \\
\text { asphyxiation. }\end{array}$ \\
\hline $\begin{array}{l}\text { Mobile plant, including mobile } \\
\text { platforms and moving traffic. }\end{array}$ & Being struck by vehicles. \\
\hline Un-leveled terrain & Trips and falls. \\
\hline $\begin{array}{l}\text { Cement products and other } \\
\text { hazardous substances. }\end{array}$ & $\begin{array}{l}\text { Dermatitis. } \\
\text { Burns. } \\
\text { Abrasion. } \\
\text { Inhalation of harmful particles. }\end{array}$ \\
\hline $\begin{array}{l}\text { Manual handling (involving } \\
\text { bending, } \\
\text { reaching, stretching, pulling, lifting, } \\
\text { repetitive motions, and awkward } \\
\text { posture). }\end{array}$ & Muscular disorders, including sprains and strains. \\
\hline Excessive noise. & Long term exposure can cause deafness. \\
\hline Vibration. & Musculoskeletal disorders \\
\hline $\begin{array}{l}\text { Heat, cold, wet and other } \\
\text { weather conditions }\end{array}$ & $\begin{array}{l}\text { Heat rashes. } \\
\text { Heat stress. } \\
\text { Dehydration. } \\
\text { Sunburn. } \\
\text { Long-term exposure to UV radiation can cause cataracts and } \\
\text { skin cancers. } \\
\text { Frostbite. } \\
\text { Hypothermia. }\end{array}$ \\
\hline Fatigue. & $\begin{array}{l}\text { Cramps. } \\
\text { Numbness. }\end{array}$ \\
\hline $\begin{array}{l}\text { Inadequate amenities e.g. } \\
\text { drinking water, toilets and } \\
\text { washing facilities. }\end{array}$ & Poor hygiene causes infections and allows them to spread. \\
\hline $\begin{array}{l}\text { Sexual harassment and } \\
\text { workplace bullying. }\end{array}$ & $\begin{array}{l}\text { Emotional stress. } \\
\text { Fear and anxiety. } \\
\text { Physical illness. }\end{array}$ \\
\hline
\end{tabular}

Source: Basic concepts of hazards and risks from ILO construction OS \& H (2015).

\section{Construction Industry Health and Safety}

In the perception of Muiruri and Mulinge, (2014) as corroborated by Mopho, (2020) workers are exposed to hazards of occupational diseases, injuries and adverse effects of excessive long hours of work, these create high risk for the workforce in the construction workplaces. These authors went further to disclose that in such workplaces, machines, 
plants including sophisticated construction equipment do pose various degrees of dangers to operators, some of whom in most cases have no prior skills for operating such equipment or plants. More so, Mopho (2020) noted that it has been discovered from research that an average of 6.5 million people are at work and on approximately 252,000 construction sites in a given day across the globe. Be that as it may, the rate of fatal injury in the construction industry did not abate rather it has gone from manageable phenomenon to a better imagined than experienced when compared to other industries.

\section{Theoretical Framework}

\subsection{Safety Theories of Accident}

Occupational safety theories of accident, models and metaphors by Swustes, Gulijk, Zwaard and Ostendorp (2014) and a literature review in three decades since World War II, in the United State Britain and Netherland include the following highlights:

1. In safety science, the medical domain became dormant after World War II

2. The theory of task dynamics; and the hazard banner-target model were developed.

3. Cause of accidents shifted from worker behaviour to task and managerial causes.

4. Complexity in process and military industry created disasters and risk assessment as tools.

5. Accident proneness remained popular in the professional safety domain.

According to Swuste, Gulijk, Zwaard and Ostendorp (2014) point of view and their research findings; the accident process theory still remains popular in the professional safety domain in the Netherlands. Based on the perception of Swuste, et al., (2014) as earlier stated Mopho (2020) concurred that safety theory can be reasonable to be an accident theory that linked safety and productivity. Elaborating the opinion of Swuste, et al., (2014), Mopho (2020) noted that incorporating a fuller accounting of tasks, the entropy model of accident causation demonstrates that safety and productivity are bound together.

To buttress the point being made by Mopho (2020) in tandem with Swuste, et al., (2014) the analogy of every firm that uses technology, people and the work site to generate a product or service was perceived as sacrosanct to the entropy model of accident causation in safety practices on account of the fact that when the process of safety practices is being undertaken these factors interact. The model according to Mopho (2020) in tandem with Swuste, et al., (2014) begins in section (1) by creating an organization in an ideal context. The firm consistently operates with perfect safety production output and system quality. All the factors here are fully and effectively utilized. In this scenario the accident rate and level of risk is zero. Ideally and in reality, however, firms operate as natural systems subjects to universal laws that cause system factors to degrade with time. For example, technology can suffer wear and tear, the physical environment becomes unstable or untidy, and infrastructure corrodes disclosed (Mopho, 2020; Swuste, et al., 2014).

Now, that, each time a process is carried out, deviations may occur that have the potential to introduce additional hazards (Mopho, 2020). Workers also experience 
degradation in the form of fatigue, variable vigilance/concentration or loss of physical capacity. Entropy is shown in section (2) of their findings as the downward dashed lines for each system factor. Running counter to the firm's interventions, system factors have a tendency to deteriorate or shift to a state that as system factors degrade, the probability of an accident rises exponentially, shown by the red lines. Mopho (2020) therefore posited that concurrently, the firm's ability to produce output at the same rate is put at risk because the quality of system factors also affects productivity. Mopho (2020) gave an example with the probability that if people (workers) are ill or fatigue, they cannot work efficiently.

Also, if equipment is not maintained it cannot generate optimum levels of output. The model shows that degradation has a negative impact on organizational safety and performance, (Swuste, et al., 2014). On Occupational Health and Safety (OHS) management, logically, it becomes obvious to ask, what are the characteristics of an OHS management system driven by the Entropy model? First what comes to the fore is, the perspective of "unsafe acts" versus "unsafe condition" proposed by other models and is replaced with a focus on systems quality, was the viewpoint of Swuste, et al. Based on the foregoing, researchers position, there is much less emphasis on human error as the cause of accidents. It acknowledged that employees do not want to be injured at work and that they rarely knowingly act in an unsafe manner on their own volition.

In Mopho (2020) as well as Swuste, et al., (2014) point of view, unsafe acts are usually symptoms of systemic problems such as insufficient skill-based training, work pressures or excessive demands from the task on the environment. They also reasoned that emphasis on worker fallibility or capability can hinder companies from exploring fully the underlying parameters that can lead to incidents. Human error is not excluded from the model because the quality of human resources contributes to the level of risk (Mopho, 2020). It may be found for instance, that an accident is caused primarily by lack of workplace specific skills (a residual risk) or by the worker operating equipment under the influence of medication (an entropic risk). Their argument is that the Entropy model allows the behavioural aspect of safety to be classified. Ideally, behavioural safety management should address the risk associated with human resources and the organizational culture that defines acceptable behaviour (Mopho, 2020; Swuste, et al., 2014). The primary objective of the culture is to develop employee competence and vigilance.

In the observed thought of Swuste, et al., (2014) a "safe worker" operates in a safety culture, therefore, it can be defined as someone who: is educated about residual risk; is vigilant because of residual risk; work safely and efficiently to keep entropic risk low; is informed of changes in entropic and residual risk; and has the knowledge and opportunity to make suggestions that contribute to improve safety (Mopho, 2020; Swuste, et al., 2014).

\subsection{Empirical Review}

Peter, Grant, Rodgers and Dennerlein (2018) carried out work on a cluster randomized controlled trial of a total worker health intervention on commercial construction sites. 
Matched pair cluster randomized controlled trial conducted on ten worksites five intervention $(n=324)$ five control sites $(n=283)$; workers surveys were collected at all sites pre and post-exposure at one- and six months. Linear and logistic regression models were used to evaluate the effect of the intervention on pain and injuries, dietary and physical activity behaviours, smoking, ergonomic practices and work limitation. They used worker groups and manager- interviews to supplement the evaluation after controlling for matched intervention and controlled pairs as well as covariates at one month following the ergonomic program, they observed a significant improvement in ergonomic practice $(B=0.20, P=0.002)$ and a reduction in incidence of pain and injury $(\mathrm{OR}=0.58, \mathrm{P}=0.012)$ in the intervention group. At six months, they observed differences in favour of the intervention group force reduction in physically demanding work $(\mathrm{B}=$ $0.25, \mathrm{P}=0.008)$ increased recreational physical activity $(\mathrm{B}=35.2, \mathrm{P}=0.026)$ including higher consumption of fruits and vegetables are barriers to intervention implementation.

In another research work carried out by other researchers Oakman and Newpane (2017) in synergy with Proper and Nyard on workplace intervention to improve work ability; a systematic review and meta-analysis of their effectiveness; they used in their work argument or statement, work-based interventions focused on individuals, the workplace, or multilevel (combination). They used work ability index (WAI) or the single-item work ability score (WAS) to measure outcome of work ability, the work under review, to synthesize the results grade (grades of recommendation, assessment, development and evaluation) criteria was used to assess evidence quality and impact statements, were developed to synthesize the results. The above researchers reasoned that meta- analysis was undertaken where appropriate. Their results showed that they reviewed 17 randomized control trials (comprising 22 articles) multilevel interventions $(n=5)$ included changes to work arrangements and causes with supervisors, whilst individual focused intervention $(n=12)$ involved behaviour change or exercise programs. They identified only evidence of a moderate quality for either individual or multilevel interventions aiming to improve work ability.

\section{Summary of Reviews}

The theoretical framework on safety theories of accident as examined in this paper portrayed the core of applicable models and metaphors of occupational risks and hazards in the construction industry and underlying concepts that should be taken into consideration to minimize construction industry risks and avert the associated hazards. In order to expatiate on the dynamics of this paper, five (5) concepts were reviewed to wit: the construction industry; safety policies, programmes and practice; safety and workplace safety; as well as construction industry health and safety. Also, empirical works were reviewed with none having complete similarity in contextual and geographical scope with the study under investigation. This is the gap this study bridged. 


\section{Methodology}

A descriptive cross-sectional design was adopted for this study. The study population consisted of 2276 workers from 10 construction companies in Rivers state. A sample of 455 construction workers was drawn using clustered sampling technique. The instrument used for data collection was a self-structured questionnaire titled, "Workplace Safety Practices Questionnaire" (WSPQ). The questionnaire was made up of sections $\mathrm{A}$ and $\mathrm{B}$. Section A contained the demographic data used to elicit information from the respondents while section B contained questionnaire items structured based on the variables of the study. The items were provided with answers on a modified Likert scale of four point ratings, thus, Always, $(\mathrm{A})=4$ point, Occasionally, $(\mathrm{O})=3$, Rarely $(\mathrm{R})=$ 2 , Never $(\mathrm{N})=1$. The instrument was validated, and reliability was carried out using a test-retest method, which was calculated with Person's Product Moment Correlation coefficient; and the reliability coefficient was 0.78 . The 455 copies of the questionnaire were administered and retrieved the same day from the respondents with the help of 6 research assistants. At the end, 380 copies of the questionnaire were completely filled and returned for data analysis representing $84 \%$. For the purpose of data analysis, numerical values were assigned to each of the response scales. Based on this, a criterion mean of 2.5 was calculated as the benchmark for accepting or rejecting the mean response of the respondents. Descriptive statistics- mean and standard deviation were used to answer the research questions while inferential statistics--ANOVA was used to test the research hypothesis.

\section{Results}

Research Question 1: What is the difference in safety practices based on location of construction companies in Rivers state, Nigeria?

Table 1: Mean and standard deviation on the difference in safety practices based on location of 10 selected construction companies in Rivers state

\begin{tabular}{|c|c|c|c|c|c|c|c|c|c|c|}
\hline & & \multicolumn{3}{|c|}{ Rural } & \multicolumn{3}{|c|}{ Semi-Urban } & \multicolumn{3}{|c|}{ Urban } \\
\hline $\mathrm{S} / \mathrm{N}$ & Variables & $\overline{\bar{X}}$ & SD & Remark & $\overline{\bar{X}}$ & SD & Remark & $\overline{\bar{X}}$ & SD & Remark \\
\hline 1 & $\begin{array}{l}\text { Parameters for Safety } \\
\text { Awareness and Safe } \\
\text { Practices }\end{array}$ & 3.98 & .15 & A & 3.80 & .60 & A & 3.67 & .84 & A \\
\hline 2 & $\begin{array}{l}\text { Safety } \\
\text { Practice }\end{array}$ & 3.70 & .44 & A & 3.29 & .51 & A & 3.47 & .78 & A \\
\hline & $\begin{array}{l}\text { Overall Grand Mean and } \\
\text { SD }\end{array}$ & 3.84 & .30 & A & 3.55 & .55 & A & 3.57 & .81 & A \\
\hline
\end{tabular}


Results in Table 1 revealed that, in parameters for health and safety awareness based on the construction companies' locations, companies in rural areas had a mean $\overline{(X)}$ range of 3.98 and standard deviation (SD) range of 0.15 . The semi-urban companies had a mean $\overline{(X)}$ of 3.80 and SD of 0.60 while companies in the urban had a mean $\overline{(X)}$ of 3.67 and SD of 0.84 . In safety practice based on the construction companies' locations, companies in rural areas had a mean $(\bar{X})$ of 3.70 and SD of 0.44 , semi-urban companies had a mean $(\bar{X})$ of 3.29 and SD of 0.51 while companies in the urban had a mean $(X)$ of 3.47 and SD of 0.78 . The remark showed that the rate of safety practices in construction companies in Rivers state differs based on location and are always carried out in the selected construction companies. Also, the overall grand mean $\overline{(X)}$ of the three locations of construction companies (rural=3.84, semi-urban=3.55, urban=3.57) and overall grand SD (rural=0.30, semi-urban $=0.55$, urban $=0.81$ ) showed the homogeneity of the respondents.

Research Question 2: What is the difference in safety practices based on size of construction companies in Rivers state, Nigeria?

Table 2: Mean and standard deviation on the difference in safety practices based on size of 10 selected construction companies

\begin{tabular}{|c|c|c|c|c|c|c|c|c|c|c|}
\hline & & \multicolumn{3}{|c|}{$\begin{array}{c}\text { Small } \\
(n=1-49)\end{array}$} & \multicolumn{3}{|c|}{$\begin{array}{l}\text { Medium } \\
(n=50-499)\end{array}$} & \multicolumn{3}{|c|}{$\begin{array}{c}\text { Large } \\
(n=500 \text { and above })\end{array}$} \\
\hline $\mathrm{S} / \mathrm{N}$ & Variables & $\bar{X}$ & SD & Remark & $\bar{X}$ & SD & Remark & $\bar{X}$ & SD & Remark \\
\hline 1 & $\begin{array}{l}\text { Parameters for Safety } \\
\text { Awareness and Safe } \\
\text { Practices }\end{array}$ & 3.93 & .39 & A & 3.72 & .77 & A & 3.65 & .81 & A \\
\hline 2 & $\begin{array}{l}\text { Safety } \\
\text { practice }\end{array}$ & 3.67 & .57 & A & 3.39 & .64 & A & 3.36 & .78 & A \\
\hline & $\begin{array}{l}\text { Overall Grand Mean } \\
\text { and SD }\end{array}$ & 3.80 & .48 & A & 3.56 & .70 & A & 3.51 & .80 & A \\
\hline
\end{tabular}

Results in Table 2 revealed that, in parameters for health and safety awareness based on sizes of construction companies, small construction companies had a mean $\overline{(X)}$ range of 3.93 and standard deviation (SD) range of 0.39 . The medium construction companies had a mean $(\bar{X})$ of 3.72 and SD of 0.77 while the large construction companies had a mean $(\bar{X})$ of 3.65 and SD of 0.81 . In safety practice based on sizes of construction companies, small construction companies had a mean $(\bar{X})$ of 3.67 and SD of 0.57. Medium construction companies had a mean $(X)$ of 3.39 and SD of 0.64 while the large construction companies had a mean $\overline{(X)}$ of 3.36 and SD of 0.78 . The remark showed that in among construction companies in Rivers state, safety practices are mostly carried out based on sizes. The overall grand mean $\overline{(X)}$ of the three identified sizes of construction companies in Rivers state (small=3.80, medium=3.56, large=3.51) and overall grand SD (small=0.48, medium $=0.70$, large $=0.80$ ) showed the homogeneity of the respondents.

\subsection{Test of Hypotheses}

Ho1: There is no significant difference in the safety practice based on location of construction companies in Rivers state, Nigeria. 
Table 3: ANOVA table on safety practices

based on location of the construction companies $(n=380)$

\begin{tabular}{|l|l|c|c|c|c|c|}
\hline \multicolumn{2}{|l|}{ Variable } & Sum of Squares & Df & Mean Square & F & Sig. \\
\hline Between Groups & 4.92 & 2 & 2.46 & 5.46 & .01 \\
\hline Within Groups & 131.61 & 378 & .45 & & \\
\hline Total & 136.53 & 380 & & & \\
\hline
\end{tabular}

Results in Table 3 revealed a p-value of 0.01 at $\mathrm{F}$ value of 5.46 indicating that location of the construction companies significantly influences safety practices. The f-cal was 5.46 and the p-value was .01 which is lower than the level of significance (0.05). This indicated that the null hypothesis was rejected. Thus, there is a significant difference in safety practices based on location of the selected construction companies in Rivers state.

Ho2: There is no significant difference in the safety practice based on size of construction companies in Rivers state, Nigeria.

Table 4: ANOVA table on safety practices

based on size of the construction companies $(n=380)$

\begin{tabular}{|l|l|c|c|c|c|c|}
\hline \multicolumn{2}{|l|}{ Variables } & Sum of Squares & Df & Mean Square & F & Sig. \\
\hline \multirow{2}{*}{} & Between Groups & 4.68 & 2 & 2.34 & 5.18 & .01 \\
\cline { 2 - 7 } & Within Groups & 131.85 & 378 & .45 & & \\
\cline { 2 - 7 } & Total & 136.53 & 380 & & & \\
\hline
\end{tabular}

Results in Table 4 revealed a p-value of 0.01 at $F$ value of 5.18 which indicated that size of most construction companies in Rivers state significantly influence safety practices. The $\mathrm{f}$-cal was 5.18 and the p-value was .01 which is lower than the level of significance (0.05).This indicated that the null hypothesis was rejected. Thus, there is a significant difference in safety practices based on size of the selected construction companies in Rivers state.

\section{Summary of Findings}

1) It showed that, the overall mean value of parameters for safety awareness and safe practices as well as safety practice based on location of construction companies was above the benchmark of this study with an average margin of 1.15 .

2) It revealed that, the overall mean value of parameters for safety awareness and safe practices as well as safety practice based on size of construction companies was above the benchmark of this study with an average margin of 1.12.

3) There is a significant difference in safety practices of construction companies in Rivers state based on location.

4) There is a significant difference in safety practices of construction companies in Rivers state based on size. 


\subsection{Discussion of Findings}

Results from the study showed that there is a high level of awareness on safe practice among management staff and staff of construction companies in Rivers state. However, the level of compliance to safety practice differs based on locations and sizes of the construction companies. More so, the study did not delve into the nitty-gritty, if you want, I can give you a call tomorrow to see the quality or quantity of available being used in any of the 10 selected companies. Notwithstanding, it was statistically observed that homogeneity of response exists across locations and sizes of construction companies as it has to do with safety practices among construction companies in Rivers state. This implies that most construction companies in Rivers state are adopting safety management systems in practical terms as readiness to bring to minimum the management system therefore highlights and emboldens the awareness of responsibilities and aspects of occupational safety as well as the impact of safety standards on the performance of organizations. Similarly, Diugwu, et al. (2012) concurred that the potency of safety management systems in construction companies depends on the existence of functional safety laws which guarantees the health, safety and welfare of workers and visitors. Olutuase, (2014) also agreed that the existing safety management system in construction companies can be better implemented when characterized by effective and proper documentation.

\section{Conclusion}

Based on the findings of this study, safety practices in construction companies is still evolving in Rivers state. As much as there are noticeable improvements from what has been reported so far as the state of construction companies' safety practice prior to year 2019 in Rivers state, more data on safety practice in Rivers state construction industry may be needed for a robust assessment.

\subsection{Recommendations}

The following recommendations were made based on the findings of the study

1) Efforts should be intensified by contracting construction firms in devising improved strategy to determine and forestall hazard inherent in a given project before embarking on it.

2) Priority should be given to the review of existing legislation on safety management in companies by the state legislature to meet the current realities of safety practices in more concise and specific details.

\subsection{Contributions to Knowledge}

Based on the findings, the study has contributed to knowledge in the following ways:

1) The study has empirically documented that the Rivers state construction industry is performing above average in safety practices based on location. 
2) It also discovered that the Rivers state construction industry is performing above average in safety practices based on size.

\title{
Conflict of Interest Statement
}

The authors declare no conflicts of interests.

\begin{abstract}
About the Authors
Ilodeami Macsoto Mopho is a Pastor and a PhD candidate of occupational health and safety in the Department of Human Kinetics and Health, University of Port Harcourt, Nigeria. Also, Mopho is an expert in Health, Safety and Environment (HSE) and an instructor with the Institute of Safety Professionals of Nigeria (ISPoN) as well as Rivers State University, Port Harcourt. Mopho has also served in Rivers state Ministry of Environment as Director, Pollution Control Department.

Ernest I. Achalu is a Professor of Health Education and Health Promotion, lecturing in the Department of Human Kinetics and Health, University of Port Harcourt, Nigeria. Additionally, Achalu is a Fellow, Institute of Safety Professionals of Nigeria (ISPoN).

Golda O. Ekenedo (PhD) is a Senior Lecturer with the Department of Human Kinetics and Health, University of Port Harcourt, Nigeria. Also, Ekenedo is a Specialist in Health Education and Health Promotion and a UNICEF consultant in School Health as well as Member, Institute of Safety Professionals of Nigeria (ISPoN).
\end{abstract}

\section{References}

Anupama, P., \& Pratibha, G. (2010). Industrial safety and environment. New Delhi: S. K. Kataria \& Sons.

Astutis, S. W. (2017). Safety and wellness programmes intrinsically linked-talking of safety. Internet. Retrieved on 8/15/17, from: https://safetyblong.astulis.com/2017/03/23/safety-and-wellness-programmesintrinsically-linked/comment.

Diugwu I. A., Dorothy L. B. and Egila A. E. (2012). Effective regulation and level of awareness; An expose of the Nigeria's construction industry. Open Journal of safety science and technology.

International Labour Organisation (2015). Health and safety hazards in the construction industry, ILO: Health, Prevention and Management.

Jain, R. K. \& Rao, S. S. (2015). Industrial safety and environmental management systems (4 $4^{\text {th }}$ edition). Delhi, India: Khana publishers.

Mopho, (2020). Workplace health promotion and safety practices of construction companies in Rivers state. An unpublished PhD Thesis, Human Kinetics and Health Education. Faculty of Education, University of Port Harcourt.

Muiruri, G. \& Mulinge, C. (2014). Health and safety management on construction projects sites in Kenya. A case study of construction projects in Nairobi country. Retrieved on 2/2/16, from: 
http://www.fig.net/resources/proceedings/figproceedingd/fig2014/papers/ts07IC/ T507k-muiruri-mulinge-6847.pdf.

Olutuase, S. O. (2014). A study of safety management in the Nigerian construction industry. Journal of Business and Management. will be applied to their work. Under the terms of this license, no permission is required from the author(s) or publisher for members of the community to copy, distribute, transmit or adapt the article content, providing a proper, prominent and unambiguous attribution to the authors in a manner that makes clear that the materials are being reused under permission of a Creative Commons License. Views, opinions and conclusions expressed in this research article are views, opinions and conclusions of the author(s). Open Access Publishing Group and European Journal of Public Health Studies shall not be responsible or answerable for any loss, damage or liability caused in relation to/arising out of conflicts of interest, copyright violations and inappropriate or inaccurate use of any kind content related or integrated into the research work. All the published works are meeting the Open Access Publishing requirements and can be freely accessed, shared, modified, distributed and used in educational, commercial and non-commercial purposes under a Creative Commons Attribution 4.0 International License (CC BY 4.0). 